\title{
Development and validation of LC-MS/MS method for determination of DNDI-VL-2098 in mouse, rat, dog and hamster blood
}

\author{
Bhavesh D Patel ${ }^{*, 1,3}$, Ritika Uppal**,1, Nageswararao Pulakundam ${ }^{1}$, Jignesh P Patel ${ }^{1}$, \\ Vikram Ramanathan ${ }^{1,2}$, Rakshit Ameta ${ }^{3}$, Delphine Launay ${ }^{4}$ \& Stéphanie Braillard ${ }^{4}$ \\ ${ }^{1}$ Drug Metabolism Pharmacokinetics \& Bioanalysis, Eurofins Advinus Ltd, 21 \& 22, Phase II, Peenya Industrial Area, Bengaluru \\ 560058, India \\ ${ }^{2}$ Current address: Sun Pharma Advanced Research Company Ltd, Vadodara 390020, Gujarat, India \\ ${ }^{3}$ Department of Chemistry, PAHER University, Udaipur 313003, Rajasthan, India \\ ${ }^{4}$ Drugs for Neglected Diseases Initiative - DNDi, 15 Chemin Louis-Dunant, 1202 Geneva, Switzerland \\ *Author for correspondence: BhaveshPatel3@eurofins.com \\ **Author for correspondence: RitikaUppalMukherjee@eurofins.com
}

\begin{abstract}
Aim: To develop a bioanalytical method to support pharmacokinetic evaluation of DNDI-VL-2098 in mouse, rat, dog and hamster following oral administration. Results \& methodology: A robust LC-MS/MS bioanalytical method was developed to quantify DNDI-VL-2098. DNDI-VL-2098 showed time-dependent recovery loss in acetonitrile precipitated plasma in all species. Acid-lysed whole blood was identified as a matrix in which recovery was stable over time. A two-step extraction procedure was used, with protein precipitation followed by liquid-liquid extraction with methyl tert-butyl ether. The assay was validated in the dynamic range of 5-5000 $\mathrm{ng} / \mathrm{ml}$ for mouse, rat and dog blood, and a fit-for-purpose method was developed for hamster. Conclusion: A specific LC-MS/MS assay for DNDI-VL-2098 was developed and validated in hemolyzed blood.
\end{abstract}

First draft submitted: 27 May 2019; Accepted for publication: 17 July 2019; Published online: 6 September 2019

Keywords: albumin-mediated metabolism • hemolyzed blood • LC-MS/MS • nitroimidazo-oxazole • plasma instability • two-step sample preparation • visceral leishmaniasis

Heterocyclic compounds containing nitro moieties are known for their antibacterial properties [1]. In particular, compounds of the nitroimidazole class have proved to be effective drugs against several anerobic and protozoan infections such as trichomoniasis, amoebiasis and giardiasis [2,3]. Their biotransformation in vivo via reduction of the nitro group results in metabolites that are known to inhibit bacterial DNA synthesis [4-6]. Other nitroheterocyclic compounds such as the nitrofurans also undergo reduction of the nitro group as a prerequisite to their antibacterial activity $[7,8]$. Recently, another class of compounds, the nitroimidazo-oxazoles has received attention. An extensively studied member of this class, delamanid (formerly called OPC-67683), which is a mycobacterial cell wall synthesis inhibitor, has been developed as a drug against multidrug resistant tuberculosis [9-11]. Delamanid undergoes 'degradation' in the presence of the plasma protein albumin to produce several metabolites [12,13] in a process that appears to differ from classical enzyme mediated metabolism. Bioanalytical methods for determination of delamanid and its metabolites in various biological matrices have been developed [14,15].

DNDI-VL-2098 (Figure 1), which also belongs to the nitroimidazo-oxazole class, shows activity in vitro and in vivo against Leishmania donovani and had potential as an agent against visceral leishmaniasis [16]. The candidate had entered the GLP toxicology studies in three preclinical species (mouse, rat and dog). However, based on toxicity data, it was decided not to progress this compound for further development. Our studies showed that the compound is unstable in plasma at ambient temperature and estimation of concentrations in plasma proved to be challenging. Multiple stabilizers were evaluated during method development to improve the stability. Our studies revealed that, following addition of acetonitrile as a precipitating agent, there is a time-dependent loss of the compound in the supernatant, which is mirrored by its association with the pellet. In this study, strategies for overcoming 
<smiles>C[C@]1(COc2ccc(OC(F)(F)F)cc2)Cn2cc([N+](=O)[O-])nc2O1</smiles>

1

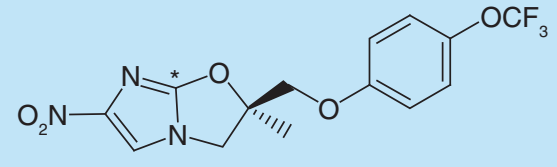

2

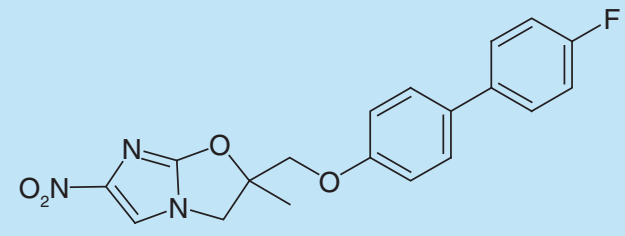

3

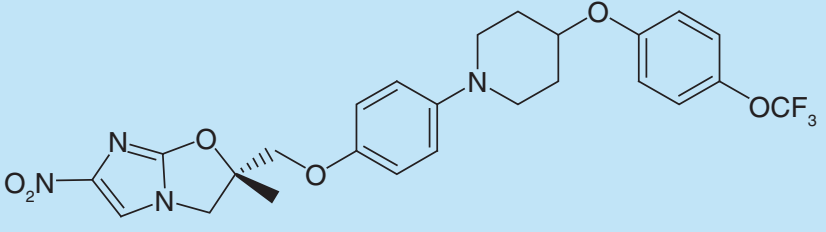

4

Figure 1. Chemical structures. (1) DNDI-VL-2098, (2) ${ }^{14}$ C-DNDI-VL-2098, (3) DNDI-VL-2075 and (4) delamanid.

the challenges seen in quantitative analysis, in particular the instability of DNDI-VL-2098 encountered during development and validation of the LC-MS/MS method, are described. We report here a specific and sensitive LC-MS/MS method for the quantitative measurement of DNDI-VL-2098 in mouse, rat, dog and hamster blood using a reverse phase column, isocratic premixed mobile phase and a two-step sample preparation procedure to achieve maximum extraction efficiency along with application of the assay to pharmacokinetic studies. The method developed and validated here prevented the ex vivo metabolism of DNDI-VL-2098 and helped in the quantification of the compound. The quantification of metabolites formed was not performed in this study.

\section{Experimental section}

Chemicals \& materials

DNDI-VL-2098 analytical standard was synthesized and characterized at Eurofins Advinus Ltd (formerly known as Advinus Therapeutics Ltd) [17]. Internal standard (IS) DNDI-VL-2075 was provided by the Auckland Cancer Society Research Centre, New Zealand. HPLC-grade acetonitrile and potassium dihydrogen phosphate were purchased from Merck. Ammonium acetate (Puriss for Mass spectrometry) and MS-grade formic acid were purchased from Merck Sigma-Aldrich (Fluka). HPLC-grade DMSO and HPLC-grade methyl tert-butyl ether were purchased from Spectrochem and JT Baker, respectively. Hydrochloric acid (AR grade) was purchased from Qualigens. ${ }^{14} \mathrm{C}-\mathrm{DNDI}-\mathrm{VL}-2098(55.71 \mathrm{mCi} / \mathrm{mmol})$ was manufactured by Selcia Limited, Essex, UK.

\section{Instrumentation \& chromatographic conditions}

Samples were analyzed on AB Sciex API 3200 and API 4000 triple-quadrupole mass spectrometers (CA, USA), Shimadzu SIL series HPLC systems (Kyoto, Japan) equipped with a degasser DGU-20A5, isopump LC-20AD, column oven CTO-10AS and an autosampler SIL-HTc. The column oven and autosampler temperature were maintained at $35 \pm 2^{\circ} \mathrm{C}$ and $4 \pm 1^{\circ} \mathrm{C}$, respectively. Volumes of 10 and $2 \mu \mathrm{l}$ processed samples were injected onto HPLC columns during analysis on API 3200 and API 4000 instruments respectively. The optimized column and mobile phase conditions for each matrix are summarized in Table 4.

The mass spectrometers were operated in positive electrospray ionization mode to monitor the MRM transitions of $m / z 360.20 \rightarrow 175.1$ and $360.20 \rightarrow 231.00$ for DNDI-VL-2098 and $m / z 370.2 \rightarrow 241.2$ for the analog IS (DNDI-VL-2075). The following mass spectrometric parameters were optimized for the study: ion spray voltage $5500 \mathrm{~V}$, source temperature $-500^{\circ} \mathrm{C}$, curtain gas $10 \mathrm{psi}$, collision gas $10 \mathrm{psi}$, nebulizing gas $30 \mathrm{psi}$, auxiliary gas 55 psi and collision energy $32 \mathrm{MeV}$ for analyte and $17 \mathrm{MeV}$ for IS. The fragmentation pattern for DNDI-VL-2098 is presented in Figure 2A. Data were acquired and analyzed using AB Sciex Analyst software version 1.5.1. 

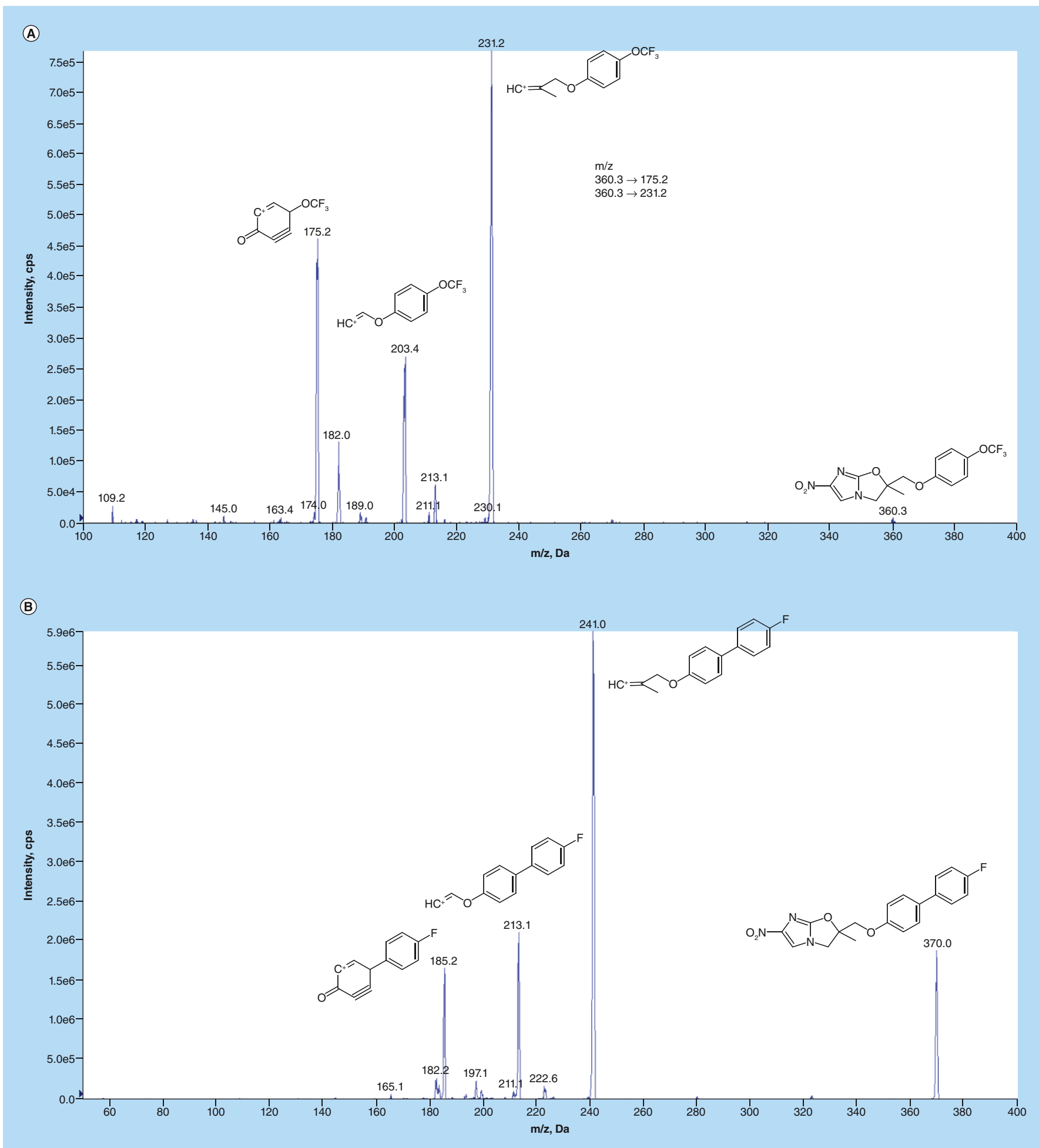

Figure 2. Mass spectra. Product ion spectra of (A) DNDI-VL-2098 and (B) DNDI-VL-2075.

Stability evaluation in mouse, rat, dog \& hamster blood \& plasma

During the initial phase of method development, the stability of DNDI-VL-2098 was assessed in mouse, rat, dog and hamster whole blood, and in plasma, followed by analysis by LC-MS/MS. The stability experiments in plasma were performed both at ambient temperature and in an ice-bath; the experiments in whole blood were performed 
at ambient temperature. Initially, whole blood and plasma were incubated at the experimental temperature for $15 \mathrm{~min}$. Following this preincubation, $2.5 \mu \mathrm{l}$ aliquots of DNDI-VL-2098 stock solutions in DMSO (300 and $80 \mu \mathrm{g} / \mathrm{ml}$ ) were spiked into $47.5 \mu \mathrm{l}$ of blood/plasma to obtain final concentrations of 15 and $4000 \mathrm{ng} / \mathrm{ml}$. The samples were then incubated for $0,0.25,0.5,1,2$ and $4 \mathrm{~h}$ at ambient temperature and in an ice-bath, and the reactions were terminated at the preset time points by addition of $400 \mu \mathrm{l}$ of acetonitrile containing IS.

The stability of DNDI-VL-2098 in whole blood and plasma was investigated in the presence of enzyme inhibitors such as sodium fluoride, EDTA, paraoxon and dichlorvos, and antioxidants such as sodium metabisulfite. Studies to understand the effect of $\mathrm{pH}$ on the stability of DNDI-VL-2098 in a biological matrix were performed in a similar fashion, with the addition of ammonia or $\mathrm{NaOH}$ to increase the $\mathrm{pH}$, and orthophosphoric acid, formic acid and hydrochloric acid to decrease the $\mathrm{pH}$. The experiment with $0.1 \mathrm{~N} \mathrm{HCl}$ was performed by premixing whole blood and plasma with $0.1 \mathrm{~N} \mathrm{HCl}$ in 1:1 (v/v) proportion, resulting in lysis of the blood cells. Following a 15-min preincubation of the lysed blood (room temperature), DNDI-VL-2098 was spiked into the acidified biological matrix to obtain final concentrations of 15 and $4000 \mathrm{ng} / \mathrm{ml}$. The samples were incubated on the bench top, and at $0,1,2$ and $4 \mathrm{~h}$ postincubation, the reactions were terminated and samples analyzed. All samples were processed by protein precipitation followed by liquid-liquid extraction and injected in LC-MS/MS as described in 'sample preparation' section.

\section{Evaluation of degradation/metabolism of DNDI-VL-2098 in Sprague-Dawley rat plasma using ${ }^{14} \mathrm{C}$ radiolabeled test compound}

A $4 \mathrm{mg}$ aliquot of ${ }^{14} \mathrm{C}$-DNDI-VL-2098 $(55.71 \mathrm{mCi} / \mathrm{mmol})$ was weighed into a $1 \mathrm{ml}$ volumetric flask and dissolved in $1 \mathrm{ml}$ methanol to prepare a $4 \mathrm{mg} / \mathrm{ml}$ or $617.2 \mu \mathrm{Ci} / \mathrm{ml}$ solution. Triplicate incubations of ${ }^{14} \mathrm{C}-\mathrm{DNDI}-\mathrm{VL}-2098$ in plasma were performed per time point for $0,2,4,6$ and $17 \mathrm{~h}$. For each incubation replicate, $2.5 \mu \mathrm{l}$ of the ${ }^{14} \mathrm{C}$ DNDi-VL-2098 stock solution $(4 \mathrm{mg} / \mathrm{ml} ; 617.2 \mu \mathrm{Ci} / \mathrm{ml})$ was spiked into $47.5 \mu \mathrm{l}$ of blank plasma in microfuge tubes. Following incubation at room temperature, the reactions were terminated at the preset time points by addition of $0.2 \mathrm{ml}$ acetonitrile. The tubes were vortexed and centrifuged in an Eppendorf centrifuge $(20,817 \mathrm{~g} ; 10$ $\min ; 4^{\circ} \mathrm{C}$ ), following which almost complete supernatants were transferred to $50 \mathrm{ml}$ Falcon centrifuge tubes and $15 \mathrm{ml}$ Hionic-Fluor scintillation cocktail (Perkin-Elmer, MA, USA) was added. After vortexing and equilibration for 30 min, radioactivity was measured on a Liquid Scintillation Analyzer (Perkin-Elmer, TRI-CARB 4910TR 110 V Liquid Scintillation Counter). About $1 \mathrm{ml}$ of sodium hypochlorite solution was added to the residue pellet in the microcentrifuge tubes, and the samples were incubated for $30 \mathrm{~min}$ at $60^{\circ} \mathrm{C}$. The resulting solutions were transferred to $50 \mathrm{ml}$ centrifuge tubes, scintillation cocktail was added and, following equilibration for $30 \mathrm{~min}$, the tubes were subjected to liquid scintillation counting. The radioactivity was not determined individually for the parent and the metabolite. The total radioactivity was determined in both the supernatant and the residue pellet using liquid scintillation counter.

\section{Method development \& validation}

Standard solutions

Two individual stock solutions $(1.0 \mathrm{mg} / \mathrm{ml})$ of DNDI-VL-2098 and one stock solution of IS DNDI-VL-2075 were made in DMSO for the preparation of calibration curve (CC) standards and quality control (QC) samples. The primary stock solutions were diluted with acetonitrile to prepare intermediate stocks and working solutions. The CC stock solution was diluted with acetonitrile to produce working solutions (WS) over the range of $100 \mathrm{ng} / \mathrm{ml}$ to $100,000 \mathrm{ng} / \mathrm{ml}$. The QC stock was diluted with acetonitrile to produce working solutions over the range of $100 \mathrm{ng} / \mathrm{ml}$ to $80,000 \mathrm{ng} / \mathrm{ml}$. The IS stock solution was diluted with acetonitrile to prepare a $5 \mu \mathrm{g} / \mathrm{ml}$ working solution.

\section{Calibration standards \& QC samples}

CC and QC samples were prepared by adding $5 \mu \mathrm{l}$ of WS to a mixture of $95 \mu \mathrm{l}$ control $\mathrm{K}_{2}$ EDTA blood and $100 \mu \mathrm{l}$ $0.1 \mathrm{~N} \mathrm{HCl}$. Control blank and zero standard samples were spiked with $5 \mu \mathrm{l}$ of acetonitrile. After vortex mixing $(20 \mathrm{~s})$ the samples were centrifuged $\left(2000 \mathrm{~g} ; 2-10^{\circ} \mathrm{C} ; 5 \mathrm{~min}\right)$. The $50 \mu \mathrm{l}$ aliquots of supernatant were spiked with the IS (20 $\mu$ l of WS). A nine-point CC (5.01, 10.02, 20.04, 57.25, 163.56, 467.31, 1335.18, 3814.80 and $5019.48 \mathrm{ng} / \mathrm{ml}$ ) was constructed by plotting the ratio of the peak areas of DNDI-VL-2098 and DNDI-VL-2075 against the nominal concentration of calibration standards in the control matrix. The data were subjected to linear regression with a $1 / \mathrm{x}^{2}$ weighting. 


\section{Sample preparation}

The sample extraction method was a two-step procedure involving protein precipitation with acetonitrile, followed by liquid-liquid extraction (LLE) of the supernatant with MTBE. Briefly, $100 \mu \mathrm{l}$ blood was diluted 1:1 with $0.1 \mathrm{~N}$ $\mathrm{HCl}$ and centrifuged $\left(2000 \mathrm{~g} ; 2-10^{\circ} \mathrm{C} ; 5 \mathrm{~min}\right)$. To a $50 \mu \mathrm{l}$ aliquot of the supernatant, $20 \mu \mathrm{l}$ of IS working solution was added, followed by $400 \mu \mathrm{l}$ of acetonitrile. After vortex mixing (30 s), the samples were centrifuged ( $2000 \mathrm{~g}$; $2-10^{\circ} \mathrm{C}$; $5 \mathrm{~min}$ ). Subsequently, $375 \mu \mathrm{l}$ of supernatant were transferred into pre-labeled RIA vials, and $100 \mathrm{mM}$ $\mathrm{KH}_{2} \mathrm{PO}_{4}$ buffer was added. Extraction was performed with MTBE to further purify the sample. A $2 \mathrm{ml}$ aliquot of MTBE was added, the contents were vortex-mixed $(5 \mathrm{~min})$ and then subjected to centrifugation $\left(2000 \mathrm{~g} ; 2-10^{\circ} \mathrm{C}\right.$; $5 \mathrm{~min}$ ). A $2 \mathrm{ml}$ aliquot of the supernatant organic phase was transferred to a clean plastic tube and evaporated to dryness under a flow of nitrogen gas at $50^{\circ} \mathrm{C}$. The residue was reconstituted with $200 \mu \mathrm{l}$ of the mobile phase, and $2 \mu \mathrm{l}$ of the reconstituted sample was injected into the LC-MS/MS system for analysis.

\section{Method validation}

Bioanalytical method validation for DNDI-VL-2098 in mouse, rat and dog blood was performed as per USFDA [18] and EMA [19] guidelines. The experiments included linearity, accuracy and precision, specificity/selectivity, stability, reinjection reproducibility, recovery, matrix effect and carryover. Conventional small molecule chromatographic method validation acceptance criteria were applied as specified in the USFDA and EMA guidance documents for bioanalytical method development and validation $[18,19]$.

Method specificity was evaluated by analyzing samples from at least six different lots of blood per species for potential interference at the LC peak region of DNDI-VL-2098 and DNDI-VL-2075. The acceptance criterion was that at least five of six lots should have $<20 \%$ area response in comparison to the mean response of the lower limit of quantification (LLOQ) sample for each matrix.

Analyte recovery was evaluated at four QC levels in hemolyzed blood. Six replicates each were prepared at the low QC (LQC, $14.90 \mathrm{ng} / \mathrm{ml}$ ), medium QC 1 (MQC1, $993.33 \mathrm{ng} / \mathrm{ml}$ ), medium QC 2 (MQC2, 1986.67 ng/ml) and high QC (HQC, $3973.33 \mathrm{ng} / \mathrm{ml}$ ) levels by spiking DNDI-VL-2098 and IS $(1.0 \mu \mathrm{g} / \mathrm{ml})$ into blank matrix. Following extraction, recovery (\%) was determined by comparing the mean peak area of extracted QC samples with that of corresponding neat samples prepared by spiking working solution into the mobile phase.

The matrix effect was determined in terms of matrix factor at two QC levels in hemolyzed blood as per the workshop/conference report published in AAPS Journal 2007 [20]. Two sets of samples at LQC and HQC were prepared $(n=6 /$ set), one containing IS and analyte spiked into extracts of blank hemolyzed blood matrix (postextraction samples), and the other containing IS, and analyte spiked into the mobile phase (neat solution samples). The matrix factor was calculated using the equation below.

$$
\text { Matrix Factor }=\left[\frac{\text { Peak area ration in post extracted samples }}{\text { Peak area ration in neat samples }}\right]
$$

Intra-assay precision and accuracy were estimated by analyzing six replicates at four different QC levels in mouse, rat and dog hemolyzed blood. Inter-assay accuracy and precision of the method were assessed in multiple analytical batches using six replicates of QCs for each run. The acceptance criterion for each back-calculated standard concentration was $85-115 \%$ accuracy from the nominal value, except for the LLOQ where it was $80-120 \%$. The precision criterion was $<15 \% \mathrm{RSD}$, except for the LLOQ where it was $<20 \%$.

Stability tests were conducted to evaluate the stability in matrix samples under different conditions. Bench-top stability $\left(\sim 5 \mathrm{~h}\right.$ ), freeze-thaw stability from -70 and $-20^{\circ} \mathrm{C}$ (five cycles or below where unstable) and long-term stability were performed at LQC and HQC levels using six replicates at each level. Reinjection reproducibility was performed on an entire batch and stability evaluated at the levels of lower limit of quantification QC (LLOQQC, $5.11 \mathrm{ng} / \mathrm{ml})$, LQC $(15.04 \mathrm{ng} / \mathrm{ml})$, MQC1 $(1002.44 \mathrm{ng} / \mathrm{ml})$, MQC2 $(2004.88 \mathrm{ng} / \mathrm{ml})$ and HQC $(4009.75 \mathrm{ng} / \mathrm{ml})$. Samples were considered stable if assay values were within the acceptable limits of accuracy.

Dilution integrity was evaluated for a 50-fold dilution with blank matrix. DNDI-VL-2098 spiked mouse, rat and dog blood samples were prepared at about $200,000 \mathrm{ng} / \mathrm{ml}$ and diluted with respective blank matrix to obtain a final concentration of about $4000 \mathrm{ng} / \mathrm{ml}$. The acceptance criterion for accuracy and precision of each diluted sample's back calculated concentration was $\pm 15 \%$ from the nominal value, and a precision of $\leq 15 \%$. 


\section{Application to rat pharmacokinetic study}

All animal experiments were approved by the Institutional Animal Ethics Committee with the approval number ATL-42-PKR/2010-056/2010. All studies were in accordance with the Committee for the Purpose of Control and Supervision of Experiments on Animals (CPCSEA), Ministry of Social Justice and Environment, Government of India.

Male Sprague-Dawley (SD) rats (220-240 g), from the Eurofins Advinus animal breeding facility, were acclimatized in the laboratory for 1 week prior to the experiments. All rats were maintained under standard environmental conditions with a $12 \mathrm{~h} \mathrm{light/dark} \mathrm{cycle.} \mathrm{Rats} \mathrm{were} \mathrm{fasted} \mathrm{overnight} \mathrm{for} 12 \mathrm{~h}$ with free access to filtered water. Food was provided $4 \mathrm{~h}$ after dose administration.

Jugular vein cannulation was performed in six rats following the method of Upton et al. [21]. DNDI-VL-2098 was administered as a solution $(20 \%[\mathrm{v} / \mathrm{v}] \mathrm{N}$-methyl-2-pyrrolidinone [NMP] $+40 \%[\mathrm{v} / \mathrm{v}]$ polyethylene glycol 400 [PEG 400] $+40 \%[\mathrm{v} / \mathrm{v}]$ citrate buffer $\mathrm{pH} 3)$ at a dose of $1 \mathrm{mg} / \mathrm{kg}$ intravenously. An oral suspension comprising $0.08 \%(\mathrm{v} / \mathrm{v})$ Tween ${ }^{\circledR} 80$ and $0.5 \%(\mathrm{w} / \mathrm{v})$ sodium carboxymethylcellulose in water was administered as oral gavage at a dose of $50 \mathrm{mg} / \mathrm{kg}$. Blood samples (approximately $120 \mu \mathrm{l}$ ) were collected from the jugular vein at pre-dose (0), 0.083 (IV only), $0.25,0.5,1,2,4,6,8,10,24,48$ and $72 \mathrm{~h}$ postdose administration into chilled microfuge tubes containing $\mathrm{K}_{2}$ EDTA anticoagulant (final concentration $4 \mathrm{mM}$ ). The samples were mixed with $\mathrm{K}_{2}$ EDTA by gentle inversion for a few seconds. A $75 \mu \mathrm{l}$ aliquot of each blood sample was immediately added to other microfuge tube containing $75 \mu \mathrm{l}$ of $0.1 \mathrm{~N} \mathrm{HCl}$ and mixed well. The samples were centrifuged at $2600 \mathrm{~g}$ for $5 \mathrm{~min}$ at $2-8^{\circ} \mathrm{C}$, and the supernatant obtained was stored below $-70^{\circ} \mathrm{C}$ until bioanalysis.

\section{Data analysis}

Blood concentration time data were analyzed by noncompartmental analysis using the validated Phoenix ${ }^{\circledR}$ WinNonlin ${ }^{\circledR}$ software (Version 6.3) and pharmacokinetic parameters were calculated. For all pharmacokinetic parameters, values were determined from individual rats and the calculated mean and standard deviation were reported. Maximum blood concentration $\left(\mathrm{C}_{\max }\right)$ and time to achieve that blood concentration $\left(\mathrm{T}_{\max }\right)$ were the observed values. The area under the blood concentration-time curve $\left(\mathrm{AUC}_{\text {last }}\right)$ was determined using the linear trapezoidal rule from time zero to the time of last measurable concentration. The area under the curve from time zero to infinity $\left(\mathrm{AUC}_{\mathrm{inf}}\right)$ was obtained by summing $\mathrm{AUC}_{\text {last }}$, and the extrapolated area determined by the ratio of the last measurable blood concentration $\left(\mathrm{C}_{\text {last }}\right)$ and the elimination rate constant $\left(\mathrm{K}_{\mathrm{el}}\right)$. The elimination rate constant $\left(\mathrm{K}_{\mathrm{el}}\right)$ was calculated from the elimination phase of the log-linear regression of blood concentration time data with a correlation coefficient $>0.80$. The terminal half-life $\left(t_{1 / 2}\right)$ was calculated using the equation $0.693 / K_{e l}$ and PK parameters, in other words, apparent volume of distribution at steady state (Vss) and clearance $(\mathrm{Cl})$ were also calculated.

\section{Results \& discussion}

Evaluation of stability of DNDI-VL-2098

Results of the stability evaluation of DNDI-VL-2098, spiked from a DMSO stock solution, into mouse, rat, dog and hamster plasma as a function of time at ambient temperature are presented in Figure 3. The results indicate a decrease in the percent remaining of DNDI-VL-2098 with time. In the case of mouse and hamster plasma, there is a $13.5 \%$ increase in the compound remaining at $0.5 \mathrm{~h}$ compared with $0.25 \mathrm{~h}$. The exact reason for this variation is unknown. The stability results in blood on wet ice are shown in Figure 3. DNDI-VL-2098 was unstable in both whole blood and plasma with only about $40 \%$ remaining at the end of $4 \mathrm{~h}$. The stability evaluation was also performed by spiking DNDI-VL-2098 prepared in 50\% acetonitrile in water into blood. However, the same trend in stability was observed suggesting no impact of DMSO on the stability in blood.

This apparent instability was further observed in experiments using ${ }^{14} \mathrm{C}$-DNDI-VL-2098 spiked into SD rat plasma (Table 1). The experiment with the radiolabeled compound was performed to understand the loss of extraction efficiency by identifying the location of the radioactivity and to imitate the loss of unlabeled parent observed with time in plasma ex vivo. The ${ }^{14} \mathrm{C}$ radioactivity in the supernatant showed a decrease at $2 \mathrm{~h}$ and thereafter remained constant up to $17 \mathrm{~h}$. In the pellet, the ${ }^{14} \mathrm{C}$ radioactivity increased from about $7 \%$ at $0 \mathrm{~h}$ to about $45 \%$ at $4 \mathrm{~h}$, and thereafter remained constant until $17 \mathrm{~h}$. The appearance of ${ }^{14} \mathrm{C}$ in the pellet mirrored its disappearance from the supernatant. This time-dependent association of ${ }^{14} \mathrm{C}$ radioactivity with the plasma protein pellet following acetonitrile precipitation could reflect intact DNDI-VL-2098 and/or its degradation/metabolism product(s) in the pellet. The experiment with the radiolabeled compound also established that the parent potentially 
(A)

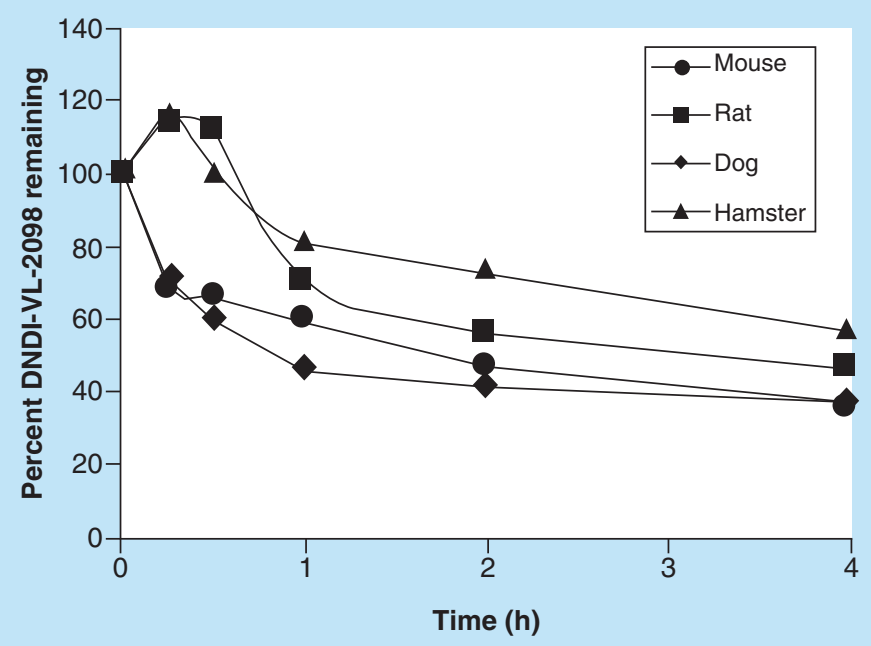

(B)

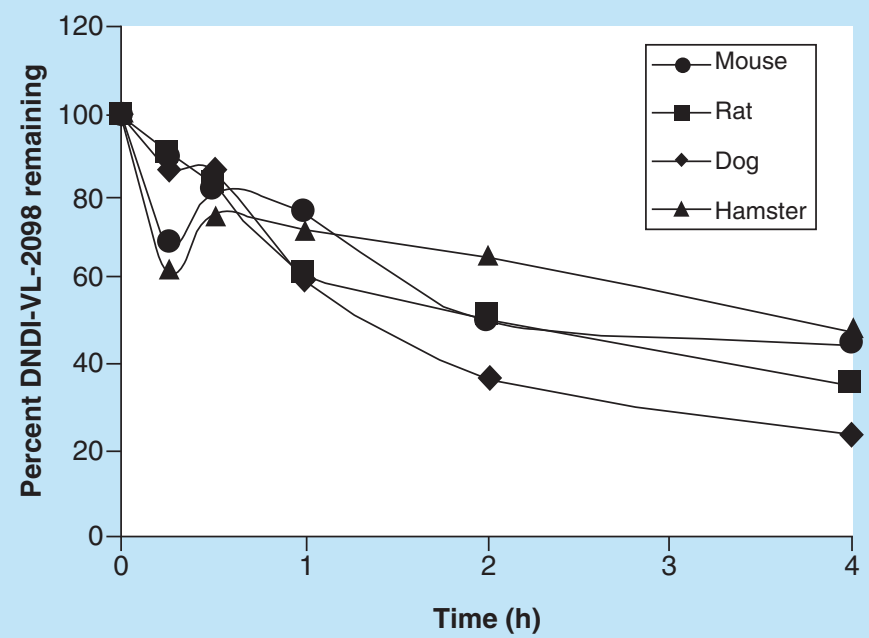

(C)

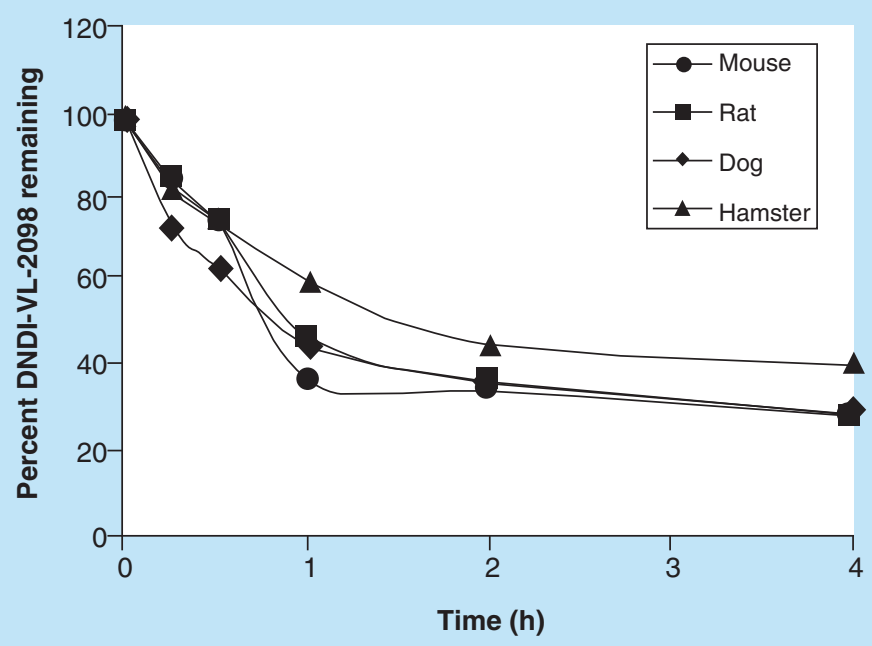

(D)

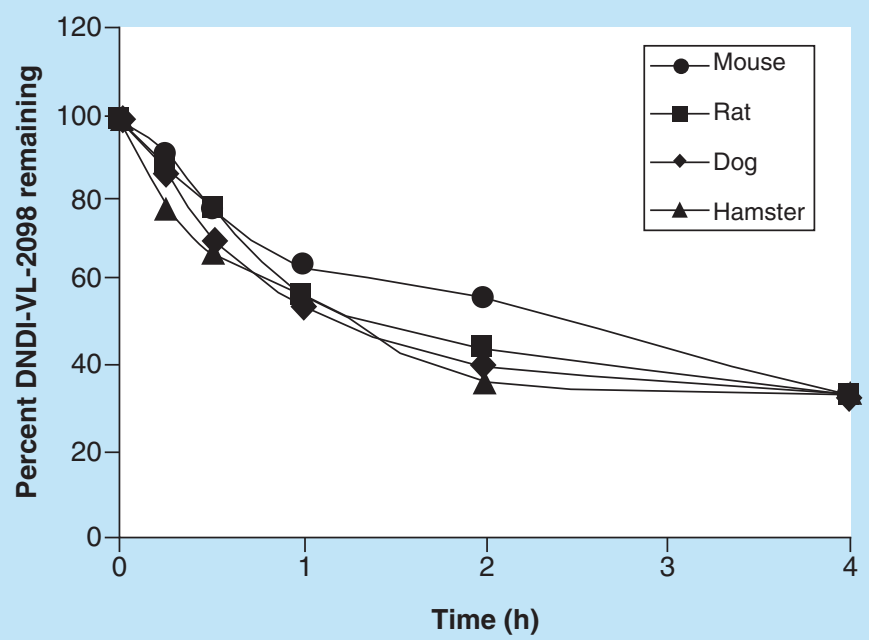

Figure 3. Stability. Percent remaining of DNDI-VL-2098 (A) low quality control level at ambient temperature; (B) high quality control level at ambient temperature; (C) low quality control level on wet ice; (D) high quality control level on wet ice.

did not metabolize into soluble metabolites, but the radiolabeled side of the structure remained in the precipitate generated in the plasma on the addition of acetonitrile. The radioactivity increased with time in the precipitate suggesting that the intact DNDI-VL-2098 and/or its degradation/metabolism product(s) may still be bound to the precipitated plasma proteins. The observations described above for DNDI-VL-2098 in spiked plasma differ from those seen for majority of compounds. For many drugs, recovery from spiked plasma precipitated with acetonitrile can be less than 100\%, and the unrecovered drug is attributed to its association with the pellet. DNDI-VL-2098 has structural similarity to delaminid which associates with albumin and catalyzes its degradation. Efforts are in progress to identify any degradation/metabolism products of DNDI-VL-2098 in the pellet.

\section{Sample processing approaches to enhance recovery}

Time-dependent recovery of DNDI-VL-2098 was observed in acetonitrile precipitated spiked plasma (Figure 3). This is contrary to what is seen for most compounds, with the exception of some ester prodrugs that are prone to the action of plasma esterases. Various approaches were assessed to address the issue including enzyme inhibitors, antioxidants and $\mathrm{pH}$ alteration (Tables $2 \& 3$ ). At the time of development, the enzyme responsible for the 


\begin{tabular}{|c|c|c|c|c|c|c|c|c|c|c|c|}
\hline \multirow{2}{*}{$\begin{array}{l}\text { Time } \\
\text { (h) }\end{array}$} & \multirow[t]{2}{*}{ Pellet (DPM) } & \multirow{2}{*}{$\begin{array}{l}\text { Supernatant } \\
\text { (DPM) }\end{array}$} & \multirow{2}{*}{$\begin{array}{l}\text { Mass balance } \\
\text { (Total DPM) }\end{array}$} & \multirow{2}{*}{$\begin{array}{l}\text { \%DPM in } \\
\text { pellet }\end{array}$} & \multirow{2}{*}{$\begin{array}{l}\text { Mean \% } \\
\text { pellet }\end{array}$} & \multicolumn{3}{|c|}{ Pellet DPM } & \multicolumn{3}{|c|}{ Supernatant DPM } \\
\hline & & & & & & Mean & SD & CV (\%) & Mean & SD & CV (\%) \\
\hline & 225122 & 2638984 & 2864106 & $7.9 \%$ & & & & & & & \\
\hline \multirow[t]{3}{*}{0} & 202435 & 2684461 & 2886896 & $7.0 \%$ & $7.2 \%$ & 206854 & 16508 & $8.0 \%$ & 2682362 & 42368 & $1.6 \%$ \\
\hline & 193005 & 2723642 & 2916647 & $6.6 \%$ & & & & & & & \\
\hline & 913331 & 1854961 & 2768292 & $33.0 \%$ & & & & & & & \\
\hline \multirow[t]{3}{*}{2} & 967453 & 1793951 & 2761404 & $35.0 \%$ & $34.4 \%$ & 959659 & 42965 & $4.5 \%$ & 1825694 & 30580 & $1.7 \%$ \\
\hline & 998194 & 1828171 & 2826365 & $35.3 \%$ & & & & & & & \\
\hline & 1279281 & 1420483 & 2699764 & $47.4 \%$ & & & & & & & \\
\hline \multirow[t]{3}{*}{4} & 1303435 & 1538777 & 2842212 & $45.9 \%$ & $45.3 \%$ & 1248297 & 75556 & $6.1 \%$ & 1509374 & 78438 & $5.2 \%$ \\
\hline & 1162174 & 1568863 & 2731037 & $42.6 \%$ & & & & & & & \\
\hline & 1221994 & 1521160 & 2743154 & $44.5 \%$ & & & & & & & \\
\hline \multirow[t]{3}{*}{6} & 1322544 & 1519789 & 2842333 & $46.5 \%$ & $46.4 \%$ & 1285421 & 55195 & $4.3 \%$ & 1483448 & 64135 & $4.3 \%$ \\
\hline & 1311726 & 1409395 & 2721121 & $48.2 \%$ & & & & & & & \\
\hline & 1281363 & 1571591 & 2852954 & $44.9 \%$ & & & & & & & \\
\hline \multirow[t]{2}{*}{17} & 1309226 & 1510235 & 2819461 & $46.4 \%$ & $45.5 \%$ & 1288460 & 18282 & $1.4 \%$ & 1545136 & 31538 & $2.0 \%$ \\
\hline & 1274791 & 1553581 & 2828372 & $45.1 \%$ & & & & & & & \\
\hline
\end{tabular}

\begin{tabular}{|c|c|c|c|c|c|}
\hline \multirow[t]{2}{*}{ Stabilizer } & \multicolumn{5}{|c|}{ \% Remaining } \\
\hline & $\mathrm{Oh}$ & $1 \mathrm{~h}$ & $2 \mathrm{~h}$ & $4 \mathrm{~h}$ & $6 \mathrm{~h}$ \\
\hline No stabilizer & 100.00 & 95.8 & 73.39 & 35.36 & 20.52 \\
\hline $1 \%$ formic acid in water to plasma $(1: 1)$ & 100.00 & 93.6 & 94.35 & 94.77 & 93.52 \\
\hline Sodium metabisulphite & 100.00 & 6.45 & 0.12 & 0 & 0 \\
\hline Denatured plasma & 100.00 & 86.65 & 44.75 & 30.28 & 12.98 \\
\hline PBS & 100.00 & 96.18 & 91.77 & 91.23 & 98.83 \\
\hline PBS $+20 \mu$ l of sodium metabisulphite & 100.00 & 50.09 & 45.03 & 41.28 & - \\
\hline Plasma harvested with $\mathrm{K}_{2}$ EDTA-formaldehyde & 100.00 & 93.8 & 96.46 & 89.93 & 84.12 \\
\hline Plasma harvested with $\mathrm{K}_{2}$ EDTA-formaldehyde-fortified with formic acid & 100.00 & 110.93 & 99.35 & 105.07 & 99.49 \\
\hline
\end{tabular}

\section{Table 3. Percent remaining of DNDI-VL-2098 in mouse, rat, dog and hamster blood with $0.1 \mathrm{~N} \mathrm{HCl}$.}

\begin{tabular}{|c|c|c|c|c|c|c|c|c|}
\hline \multirow[t]{2}{*}{ Time (h) } & \multicolumn{2}{|c|}{ Mouse } & \multicolumn{2}{|c|}{ Rat } & \multicolumn{2}{|c|}{ Dog } & \multicolumn{2}{|c|}{ Hamster } \\
\hline & LQC & HQC & LQC & HQC & LQC & HQC & LQC & HQC \\
\hline 0 & 100.00 & 100 & 100 & 100 & 100 & 100 & 100 & 100 \\
\hline 1 & 100.00 & 100.26 & 98.61 & 104.14 & 94.12 & 91.48 & 99.61 & 108.05 \\
\hline 2 & 90.14 & 104.90 & 101.47 & 109.43 & 90.05 & 101.24 & 107.07 & 107.53 \\
\hline 4 & 85.22 & 106.31 & 87.87 & 105.66 & 97.90 & 108.59 & 97.99 & 105.23 \\
\hline
\end{tabular}

$\mathrm{LQC}=14.90 \mathrm{ng} / \mathrm{ml}, \mathrm{HQC}=3973.33 \mathrm{ng} / \mathrm{ml}$.

HQC: High quality control; LQC: Low quality control.

degradation of the compound was not established and hence various enzyme inhibitors were screened. The enzyme inhibitors, like sodium fluoride, paraoxon and dichlorvos, are known for their esterase activity and inhibition against enzymes such as acid phosphatases and serine/threonine proteases. Addition of enzyme inhibitors including sodium fluoride, EDTA, paraoxon and dichlorvos, use of antioxidants such as sodium metabisulfite, and alkalinization of the matrix $\mathrm{pH}$ with ammonia or $\mathrm{NaOH}$ did not resolve the stability issue. On the contrary, there was an increase in compound stability in experiments where the $\mathrm{pH}$ of the matrix was reduced with orthophosphoric acid, formic acid and hydrochloric acid (Tables $2 \& 3$ ). However, use of formic acid resulted in gel formation upon freezing and thawing of samples, hampering its use, and orthophosphoric acid resulted in a 'dirty' sample (brownish in color 
Table 4. Chromatographic conditions in mouse, rat, dog and hamster blood.

\begin{tabular}{|c|c|c|c|}
\hline \multirow[t]{2}{*}{ Chromatographic parameters } & \multicolumn{3}{|c|}{ Biological species } \\
\hline & Sprague-Dawley rat and hamster & Beagle dog & Swiss albino mouse \\
\hline Column & $\begin{array}{l}\text { Kromasil C8, } 4.6 \times 50 \mathrm{~mm}, 5 \mu \mathrm{m} \text { particle } \\
\text { size }\end{array}$ & $\begin{array}{l}\text { Kromasil C8, } 50 \times 4.6 \mathrm{~mm}, 5 \mu \mathrm{m} \text { particle } \\
\text { size }\end{array}$ & $\begin{array}{l}\text { BDS Hypersil C18, } 150 \times 4.6 \mathrm{~mm}, 5 \mu \mathrm{m} \\
\text { particle size }\end{array}$ \\
\hline Mobile phase & $\begin{array}{l}\text { Isocratic, premixed, } 5 \mathrm{mM} \text { ammonium } \\
\text { acetate: acetonitrile, } 20: 80 \%, \mathrm{v} / \mathrm{v} \text { with } \\
0.05 \% \text { formic acid }\end{array}$ & $\begin{array}{l}\text { Isocratic, premixed, } 5 \mathrm{mM} \text { ammonium } \\
\text { acetate: acetonitrile, } 20: 80 \%, \mathrm{v} / \mathrm{v}\end{array}$ & $\begin{array}{l}\text { Isocratic, premixed, } 2 \mathrm{mM} \text { ammonium } \\
\text { acetate: acetonitrile, 10:90\%, v/v; with } \\
0.05 \% \text { formic acid }\end{array}$ \\
\hline Flow rate $(\mathrm{ml} / \mathrm{min})$ & 0.60 & 0.80 & 1.00 \\
\hline Run time (min) & 3.5 & 5.0 & 4.5 \\
\hline Retention times of DNDI-VL-2098 (min) & $\sim 1.40$ & $\sim 1.09$ & $\sim 1.80$ \\
\hline Retention time of DNDI-VL-2075 (min) & $\sim 1.40$ & $\sim 1.12$ & $\sim 1.80$ \\
\hline
\end{tabular}

after extraction). Eventually, further experimentation showed that instability could be overcome by acidification of blood or plasma with $0.1 \mathrm{~N} \mathrm{HCl}$ (Tables $2 \& \& 3$ ).

The loss of the drug was time dependent as shown in Figure 3 and necessitated a shorter sample processing time. For this reason, blood was selected as the matrix for determination of in vivo pharmacokinetic parameters. The choice of blood as the matrix eliminated the centrifugation and transfer steps required to obtain plasma and thus reduced the sample processing time. Blood samples were immediately hemolyzed postcollection by the addition of $0.1 \mathrm{~N} \mathrm{HCl}$. The acid in the samples served to quench the degradation reaction, presumably by denaturing the plasma proteins.

In addition, further bioanalytical method development studies indicated that the hemolyzed blood samples exhibited a significant matrix effect in LC-MS/MS analysis. The matrix effect could potentially be due to interference from endogenous phospholipids. A few approaches were evaluated to eliminate the matrix effect. Solid phase extraction was initially attempted; however, adequate cleanup of the sample was not achieved. Subsequently, a two-step processing protocol was devised. The first step included addition of acetonitrile to precipitate the proteins in the hemolyzed acidified blood. In the second step, the supernatant from the first step was subjected to liquidliquid extraction. Several solvents such as MTBE, ethyl acetate and hexane were assessed for extraction efficiency. Maximum recovery and significant reduction in matrix interference were achieved with MTBE, which was then used for further experiments.

\section{LC-MS/MS method development}

Reverse phase chromatography proved to be ideal for achieving retention of DNDI-VL-2098. Challenges relating to analyte retention and interference, potentially due to endogenous phospholipids, were overcome by identifying appropriate columns for the matrices. A C8 column proved optimal for rat, hamster and dog blood, while a C18 column was more suitable for mouse blood. Representative chromatograms of blank and spiked blood samples are presented in Figure 4. An isocratic premixed mobile phase distinct for the different species (Table 4) was used to achieve adequate separation between the endogenous compounds and DNDI-VL-2098. Carryover was eliminated for all the matrices using the mobile phase as a rinsing solution $(1 \mathrm{ml})$. The mass parameters were optimized in positive ion detection mode for the protonated molecular ions, $m / z 360.20$ and 370.2, respectively, for DNDI-VL2098 and DNDI-VL-2075. The most abundant daughter ion was selected and optimized MRM reaction pairs of $m / z 360.20 \rightarrow 175.1$ and $360.20 \rightarrow 231.00$ for DNDI-VL-2098, and $m / z 370.2 \rightarrow 241.2$ for IS DNDI-VL-2075 were used for quantification. The fragmentation patterns of DNDI-VL-2098 and DNDI-VL-2075 are presented in Figure 2.

\section{LC-MS/MS method validation}

Linearity of the standards was established in the concentration range of $5.01-5019.48 \mathrm{ng} / \mathrm{ml}$ in mouse, rat and dog hemolyzed blood. Different weighting factors were evaluated and best fit curve was observed with $1 / \mathrm{x}^{2}$ weighting. The fit to a linear regression curve with $1 / \mathrm{x}^{2}$ weighting showed a correlation coefficient $\mathrm{r}^{2}$ of $\geq 0.99$ in all cases [22]. All calibration standards showed deviation from nominal of $\leq 15 \%$. 
(A)
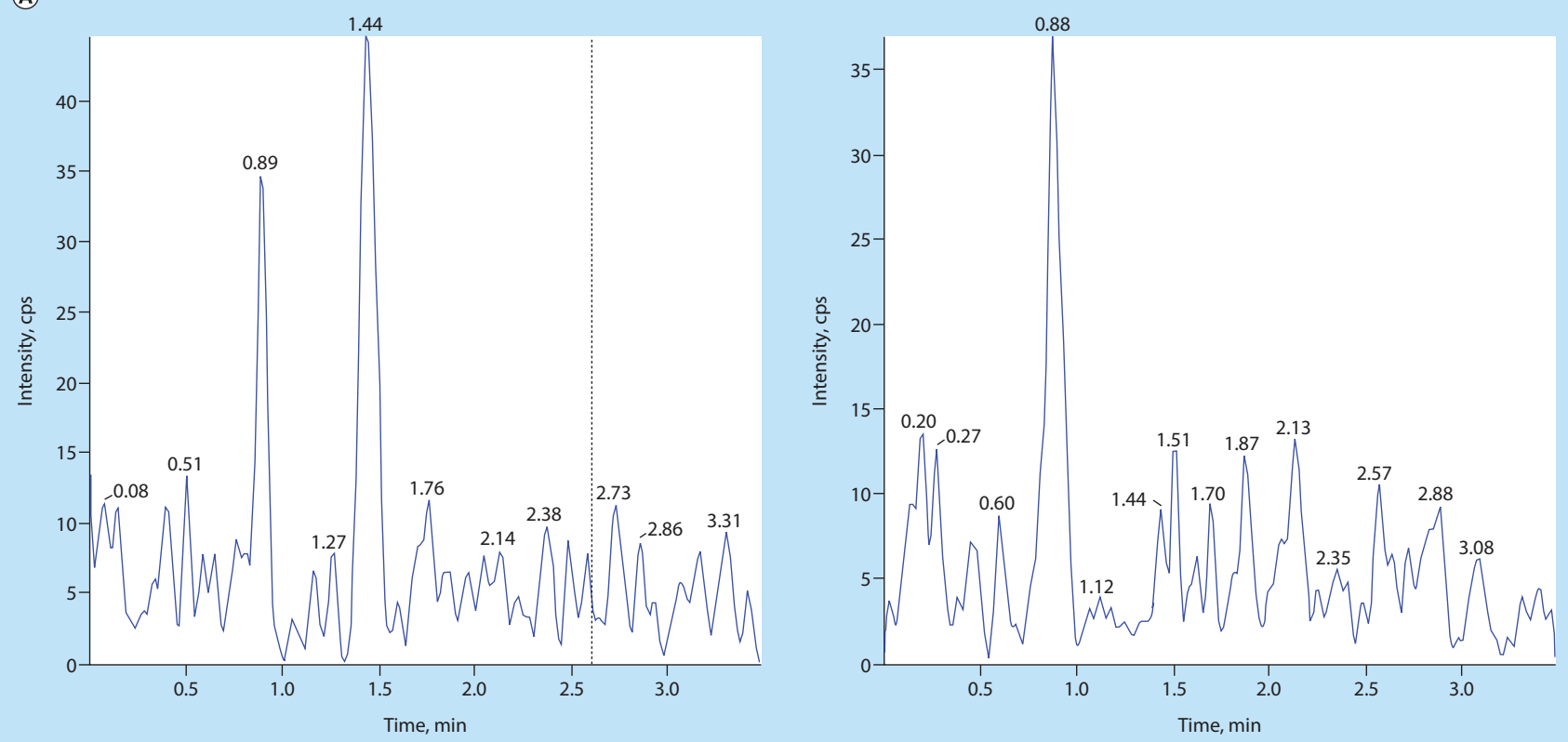

(B)
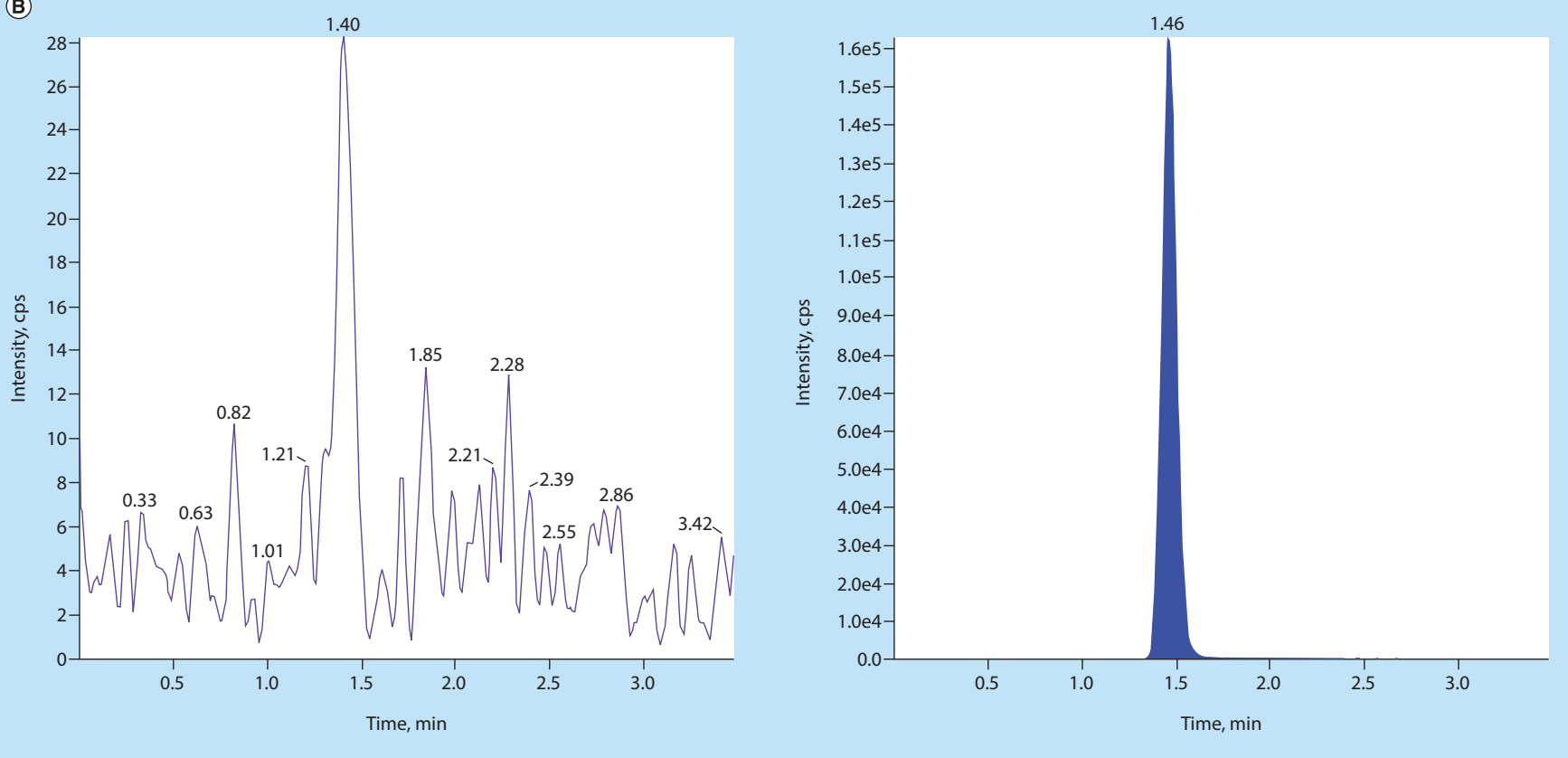

Figure 4. MRM chromatograms. Representative MRM chromatograms of DNDI-VL-2098 in (A) rat blood (blank); (B) rat blood spiked only with IS; (C) rat blood spiked with DNDI-VL-2098 at LLOQ and IS and (D) rat blood spiked with DNDI-VL-2098 at ULOQ and IS; (E) Sample from rat pharmacokinetic study.

IS: Internal standard; LLOQ: Lower limit of quantification; ULOQ: Upper limit of quantification.

\section{Specificity \& selectivity}

Figures $3 \& 4$ show representative chromatograms for blank and analyte spiked blood. No peaks were observed at the retention time of the analyte or the IS in any of the six lots of blood analyzed for specificity in each species. The area response in the blank at the retention time of the analyte was $<20 \%$ of the mean response of the LLOQ sample for each matrix. 


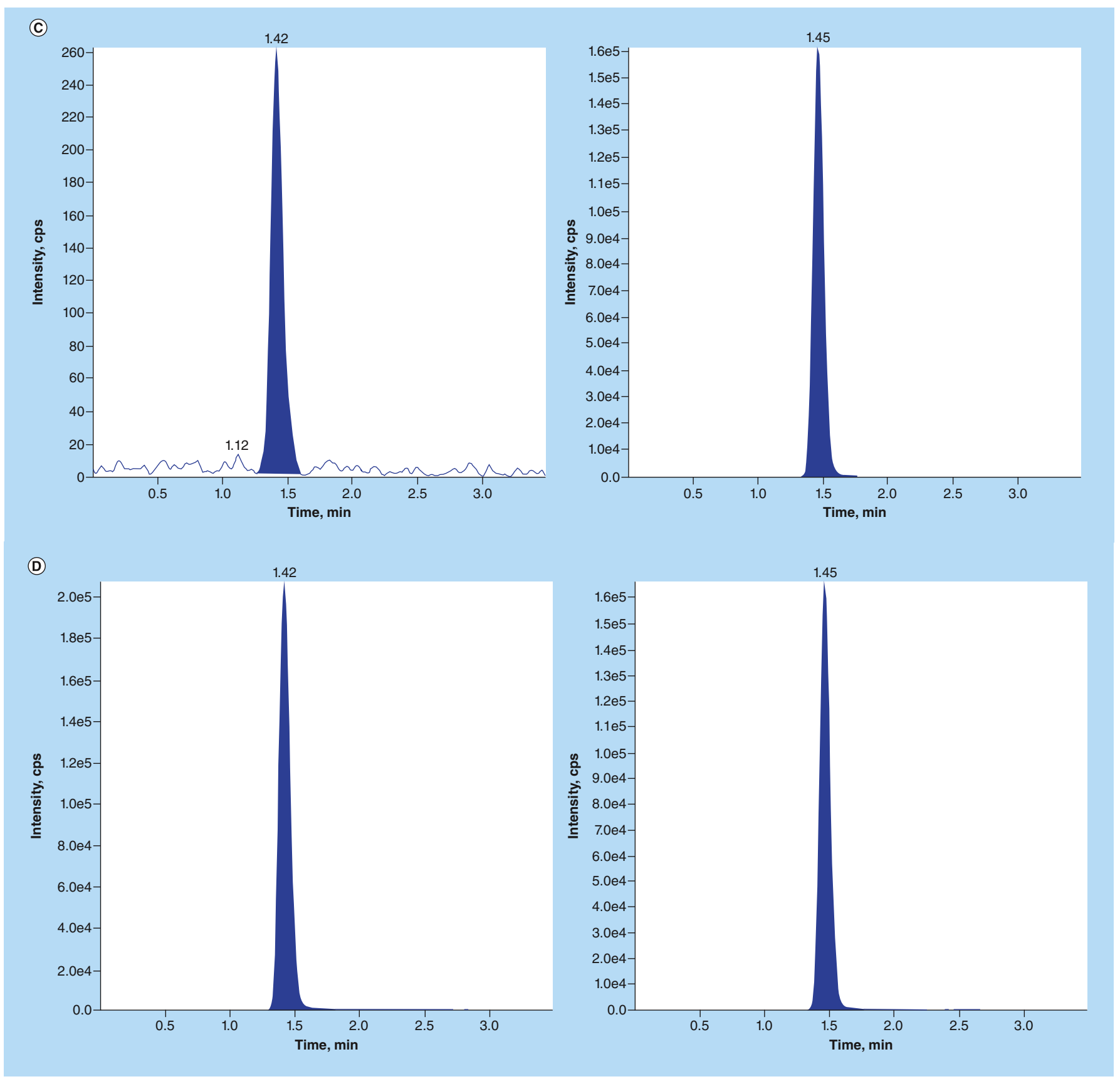

Figure 4. MRM chromatograms (cont.). Representative MRM chromatograms of DNDI-VL-2098 in (A) rat blood (blank); (B) rat blood spiked only with IS; (C) rat blood spiked with DNDI-VL-2098 at LLOQ and IS and (D) rat blood spiked with DNDI-VL-2098 at ULOQ and IS; (E) Sample from rat pharmacokinetic study.

IS: Internal standard; LLOQ: Lower limit of quantification; ULOQ: Upper limit of quantification.

The selectivity of the method, in other words, the assessment of whether the selected chromatographic peak is the analyte of interest, was established by determining the $\mathrm{S} / \mathrm{N}$ ratio of blank matrix spiked with analyte solution at LLOQ concentration. The observed $\mathrm{S} / \mathrm{N}$ ratio for the individual LLOQ samples in all species was $\geq 5$.

\section{Matrix effect}

Although sample extraction by protein precipitation with acetonitrile resulted in sufficient and consistent recovery, a significant matrix effect was observed initially in the chromatography, prompting further sample clean up. This task was accomplished by liquid-liquid extraction with MTBE after protein precipitation. The matrix effect 


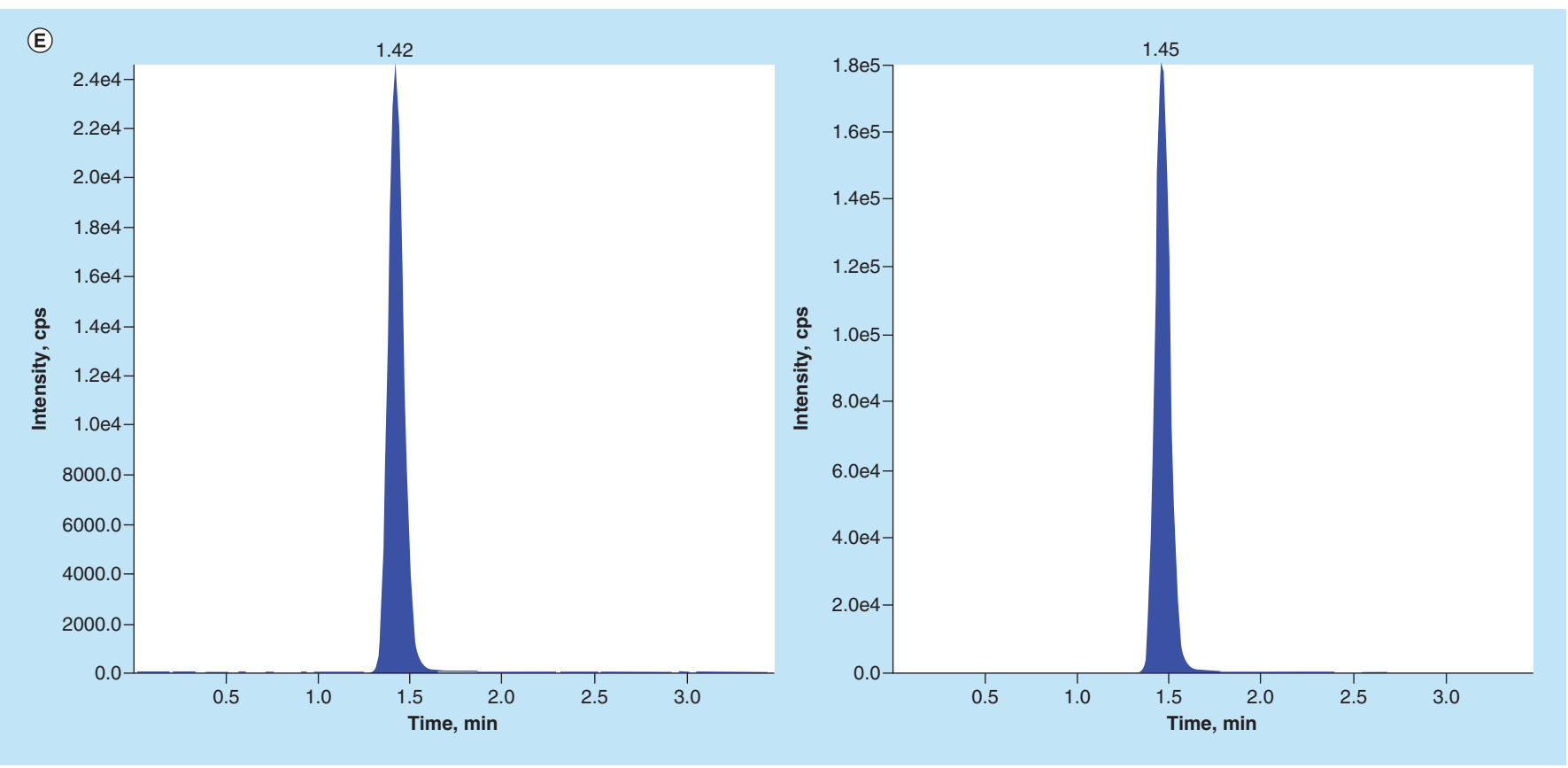

Figure 4. MRM chromatograms (cont.). Representative MRM chromatograms of DNDI-VL-2098 in (A) rat blood (blank); (B) rat blood spiked only with IS; (C) rat blood spiked with DNDI-VL-2098 at LLOQ and IS and (D) rat blood spiked with DNDI-VL-2098 at ULOQ and IS; (E) Sample from rat pharmacokinetic study.

IS: Internal standard; LLOQ: Lower limit of quantification; ULOQ: Upper limit of quantification.

\section{Table 5. Extraction recovery and matrix factor for DNDI-VL-2098 and DNDI-VL-2075 from rat, mouse and dog blood.}

\begin{tabular}{|c|c|c|c|c|c|c|c|}
\hline \multirow[t]{2}{*}{ Analyte/IS } & & \multicolumn{2}{|c|}{ Rat blood } & \multicolumn{2}{|c|}{ Mouse blood } & \multicolumn{2}{|c|}{ Dog blood } \\
\hline & & Recovery & MF & Recovery & MF & Recovery & MF \\
\hline & LQC & $52.10 \%$ & 1.03 & $60.66 \%$ & 1.04 & $58.97 \%$ & 1.04 \\
\hline \multirow[t]{3}{*}{ DNDI-VL-2098 } & MQC1 & $52.90 \%$ & - & $64.97 \%$ & - & $48.90 \%$ & - \\
\hline & MQC2 & $57.00 \%$ & - & $68.32 \%$ & - & $50.79 \%$ & - \\
\hline & HQC & $59.10 \%$ & 0.98 & $66.64 \%$ & 0.99 & $55.13 \%$ & 1.00 \\
\hline DNDI-VL-2075 & & $58.15 \%$ & & $75.30 \%$ & & $66.59 \%$ & \\
\hline
\end{tabular}

LQC $=14.90 \mathrm{ng} / \mathrm{ml}, \mathrm{MQC1}=993.33 \mathrm{ng} / \mathrm{ml}, \mathrm{MQC2}=1986.67 \mathrm{ng} / \mathrm{ml}, \mathrm{HQC}=3973.33 \mathrm{ng} / \mathrm{ml}$.

HQC: High quality control; LQC: Low quality control; MF: Matrix factor; MQC: Medium quality control.

was investigated in terms of matrix factor using the postextraction spike method and ranged from 0.98 to 1.04 (Table 5) in different species, and was within acceptance criteria of 0.85 to 1.15 , indicating that ion suppression or enhancement from the biological matrix was negligible when using the two-step sample extraction method.

\section{Recovery}

Recovery values in the different matrices at different QC levels are presented in Table 5 . The recovery of DNDIVL-2098 ranged from 48.90 to $68.32 \%$ and that of DNDI-VL-2075 ranged from 58.15 to $75.30 \%$. The two-step sample preparation procedure was adequate to achieve sample clean-up and consistent recovery across the CC range.

\section{Accuracy \& precision}

Accuracy and precision data for intraday and interday blood samples are presented in Table 6. Intraday and interday accuracy and precision values in all biological matrices were found to be within acceptable limits. For the LLOQ QC level, the intraday precision was $14.75 \%$ or less, while for the other QCs it was $11.19 \%$ or less. The interday precision for the LLOQ QC was $\leq 17.54 \%$ and for the other QCs, it was $\leq 10.25 \%$. The accuracy for all the 
Table 6. Intra- and interday precision and accuracy determination of DNDI-VL-2098 in rat, mouse and dog blood.

\begin{tabular}{|c|c|c|c|c|c|c|c|c|c|c|}
\hline \multirow[t]{2}{*}{ QC level } & \multirow{2}{*}{$\begin{array}{l}\text { Nominal con- } \\
\text { centration } \\
(\mathrm{ng} / \mathrm{ml})\end{array}$} & \multicolumn{3}{|c|}{ Mean \pm SD } & \multicolumn{3}{|c|}{ RSD $^{\dagger}$} & \multicolumn{3}{|c|}{ Accuracy (\%) } \\
\hline & & Rat blood & Mouse blood & Dog blood & Rat blood & $\begin{array}{l}\text { Mouse } \\
\text { blood }\end{array}$ & Dog blood & Rat blood & $\begin{array}{l}\text { Mouse } \\
\text { blood }\end{array}$ & Dog blood \\
\hline \multicolumn{11}{|c|}{ Intraday variation (six replicates at each concentration) } \\
\hline LLOQC & 5.07 & $5.52 \pm 0.47$ & $5.25 \pm 0.51$ & $4.88 \pm 0.72$ & 8.51 & 9.71 & 14.75 & 108.88 & 103.55 & 96.25 \\
\hline LQC & 14.90 & $13.29 \pm 0.82$ & $15.91 \pm 0.86$ & $12.96 \pm 1.45$ & 6.17 & 5.41 & 11.19 & 89.19 & 106.64 & 86.86 \\
\hline MQC1 & 993.33 & $987.27 \pm 12.45$ & $1063.45 \pm 40.33$ & $874.59 \pm 26.26$ & 1.26 & 3.79 & 3.00 & 99.39 & 106.92 & 87.93 \\
\hline MQC2 & 1986.67 & $1862.40 \pm 47.87$ & $2099.11 \pm 34.61$ & $1779.64 \pm 47.72$ & 2.57 & 1.65 & 2.68 & 93.74 & 105.53 & 89.47 \\
\hline HQC & 3973.33 & $3822.36 \pm 86.14$ & $3720.57 \pm 325.80$ & $3543.34 \pm 182.84$ & 2.25 & 8.76 & 5.16 & 96.20 & 93.52 & 89.06 \\
\hline \multicolumn{11}{|c|}{ Interday variation (18 replicates at each concentration) } \\
\hline LLOQC & 5.07 & $5.03 \pm 0.60$ & $4.94 \pm 0.69$ & $4.79 \pm 0.84$ & 11.93 & 13.97 & 17.54 & 99.21 & 97.44 & 94.48 \\
\hline LQC & 14.90 & $13.47 \pm 0.86$ & $15.10 \pm 1.21$ & $13.28 \pm 1.17$ & 6.38 & 8.01 & 8.81 & 90.40 & 101.21 & 89.01 \\
\hline MQC1 & 993.33 & $984.80 \pm 66.49$ & $1042.84 \pm 39.67$ & $1012.68 \pm 103.85$ & 6.75 & 3.80 & 10.25 & 99.14 & 104.85 & 101.82 \\
\hline MQC2 & 1986.67 & $1939.67 \pm 160.52$ & $2024.10 \pm 73.54$ & $1951.00 \pm 136.65$ & 8.28 & 3.63 & 7.00 & 97.63 & 101.75 & 98.08 \\
\hline HQC & 3973.33 & $3815.37 \pm 210.44$ & $3690.93 \pm 192.79$ & $3809.82 \pm 240.71$ & 5.52 & 5.22 & 6.32 & 96.02 & 92.77 & 95.76 \\
\hline \multicolumn{11}{|c|}{$\begin{array}{l}\dagger \mathrm{TSD}=\mathrm{SD} \times 100 / \text { mean. } \\
\mathrm{LQC}=14.90 \mathrm{ng} / \mathrm{ml}, \mathrm{MQC} 1=993.33 \mathrm{ng} / \mathrm{ml}, \mathrm{MQC2}=1986.67 \mathrm{ng} / \mathrm{ml}, \mathrm{HQC}=3973.33 \mathrm{ng} / \mathrm{ml} . \\
\text { HQC: High quality control; LQC: Low quality control; MQC: Medium quality control; SD: Standard deviation. }\end{array}$} \\
\hline
\end{tabular}

\begin{tabular}{|c|c|c|c|}
\hline Nominal concentration ng/ml & Stability & Mean $(n=6)$ & Accuracy (\%) \\
\hline LQC $=14.9$ & $\begin{array}{l}5 \text { h } 23 \text { min (bench-top) } \\
4 \text { cycles (freeze-thaw) }-20^{\circ} \mathrm{C} \\
4 \text { cycles (freeze-thaw) }-70^{\circ} \mathrm{C} \\
63 \text { days (long term) }-20^{\circ} \mathrm{C} \\
63 \text { days (long term) }-70^{\circ} \mathrm{C}\end{array}$ & $\begin{array}{l}13.65 \\
15.12 \\
15.69 \\
16.07 \\
15.94\end{array}$ & $\begin{array}{l}91.61 \\
101.48 \\
105.30 \\
107.85 \\
106.98\end{array}$ \\
\hline $\mathrm{HQC}=3973.33$ & $\begin{array}{l}5 \text { h } 23 \text { min (bench-top) } \\
4 \text { cycles (freeze-thaw) }-20^{\circ} \mathrm{C} \\
4 \text { cycles (freeze-thaw) }-70^{\circ} \mathrm{C} \\
63 \text { days (long term) }-20^{\circ} \mathrm{C} \\
63 \text { days (long term) }-70^{\circ} \mathrm{C}\end{array}$ & $\begin{array}{l}3851.31 \\
3693.84 \\
3768.86 \\
3790.61 \\
3605.64\end{array}$ & $\begin{array}{l}96.93 \\
92.97 \\
94.85 \\
95.40 \\
90.75\end{array}$ \\
\hline $\begin{array}{l}\text { LLOQQC }=5.11 \\
\text { LQC }=15.04 \\
\text { MQC } 1=1002.44 \\
\text { MQC2 }=2004.88 \\
\text { HQC }=4009.75\end{array}$ & $64 \mathrm{~h}$ (reinjection reproducibility) at $4^{\circ} \mathrm{C}$ & $\begin{array}{l}5.47 \\
16.69 \\
1060.01 \\
2239.26 \\
4332.96\end{array}$ & $\begin{array}{l}107.05 \\
110.97 \\
105.74 \\
111.69 \\
108.06\end{array}$ \\
\hline
\end{tabular}

HQC: High quality control; LQC: Low quality control; MQC: Medium quality control.

QCs was $\geq 86.86 \%$. These results indicate that the method was accurate and precise for quantitative analysis of DNDI-VL-2098 in mouse, rat and dog blood.

\section{Stability}

Stability results obtained under various experimental conditions are summarized in Tables 7-9. Storage times shown in the stability data tables were the longest period tested that met the acceptance criteria (mean value within 15\% of the nominal concentration). The bench-top stability was evaluated for $5 \mathrm{~h}$ in rat and human blood, whereas it was evaluated for $22 \mathrm{~h}$ in mouse blood to understand any effects at longer duration of time. DNDI-VL-2098 was stable in the extracted samples in mouse, rat and dog blood assessed at room temperature and following multiple freeze-thaw cycles from -70 and $-20^{\circ} \mathrm{C}$ to room temperature. The processed samples, evaluated at low and high QC levels, were also found to be stable at the autosampler temperature. The reinjection reproducibility evaluated by reinjecting stored $\left(4 \pm 2^{\circ} \mathrm{C}\right)$ calibrator, and QC extracts from the previous day's accuracy and precision batch indicated stability for up to at least $42 \mathrm{~h} 48 \mathrm{~min}$. In addition, the stock and working solutions of DNDI-VL-2098, and IS DNDI-VL-2075 in DMSO, were stable for up to 63 days when stored at $2-8^{\circ} \mathrm{C}$.

\section{Dilution integrity}

The results for the dilution integrity experiments are summarized in Table 10. Dilution integrity was confirmed 
Table 8. Stability data of DNDI-VL-2098 in Swiss Albino mouse blood.

\begin{tabular}{|llll|}
\hline Nominal concentration $\mathrm{ng} / \mathrm{ml}$ & Stability & Mean $(\mathbf{n}=6)$ & Accuracy $(\%)$ \\
\hline LQC $=14.92$ & $22 \mathrm{~h} 23$ min (bench-top) & 17.03 & 114.14 \\
& 5 cycles (freeze-thaw) $-20^{\circ} \mathrm{C}$ & 13.99 & 93.77 \\
& 5 cycles (freeze-thaw) $-70^{\circ} \mathrm{C}$ & 14.88 & 96.73 \\
& 41 days (long term) $-20^{\circ} \mathrm{C}$ & 14.42 & 90.68 \\
\hline HQC $=3978.41$ & 41 days (long term) $-70^{\circ} \mathrm{C}$ & 13.53 & 91.26 \\
& $22 \mathrm{~h} 23$ min (bench-top) & 3630.61 & 89.58 \\
& 5 cycles (freeze-thaw) $-20^{\circ} \mathrm{C}$ & 3563.72 & 93.46 \\
& 5 cycles (freeze-thaw) $-70^{\circ} \mathrm{C}$ & 3718.04 & 95.03 \\
\hline LLOQQC $=5.07$ & 41 days (long term) $-20^{\circ} \mathrm{C}$ & 3780.62 & 94.39 \\
LQC $=14.92$ & 41 days (long term) $-70^{\circ} \mathrm{C}$ & 3755.22 & 109.86 \\
MQC1 $=994.60$ & $45 \mathrm{~h}$ 9 min (reinjection reproducibility) & 5.57 & 113.27 \\
MQC2 $=1989.20$ & at $4{ }^{\circ} \mathrm{C}$ & 16.90 & 99.25 \\
HQC $=3978.41$ & & 987.10 & 99.36 \\
\hline
\end{tabular}

\section{Table 9. Stability data of DNDI-VL-2098 in Beagle dog blood.}

\begin{tabular}{|llll|}
\hline Nominal concentration $(\mathbf{n g} / \mathrm{ml})$ & Stability & Mean $(\mathbf{n}=\mathbf{6})$ & Accuracy $(\%)$ \\
\hline LQC $=14.92$ & $5 \mathrm{~h}$ 04 min (bench-top) & 13.57 & 90.95 \\
& 5 cycles (freeze-thaw) $-20^{\circ} \mathrm{C}$ & 14.89 & 99.80 \\
& 5 cycles (freeze-thaw) $-70^{\circ} \mathrm{C}$ & 15.54 & 104.16 \\
\hline LQC $=14.13$ & 23 days (long term) $-20^{\circ} \mathrm{C}$ & 15.23 & 107.78 \\
& 34 days (long term) $-70^{\circ} \mathrm{C}$ & 13.04 & 102.29 \\
\hline HQC $=3978.41$ & $5 \mathrm{~h}$ 04 min (bench-top) & 3909.58 & 98.27 \\
& 5 cycles (freeze-thaw) $-20^{\circ} \mathrm{C}$ & 4185.45 & 105.20 \\
\hline HQC $=3990.00$ & 5 cycles (freeze-thaw) $-70^{\circ} \mathrm{C}$ & 4199.40 & 105.55 \\
& 23 days (long term) $-20^{\circ} \mathrm{C}$ & 3711.32 & 93.02 \\
\hline LLOQQC $=5.07$ & 34 days (long term) $-70^{\circ} \mathrm{C}$ & 3619.87 & 90.72 \\
LQC $=14.92$ & $42 \mathrm{~h} 48$ min (re-injection & 5.63 & 111.05 \\
MQC1 $=994.60$ & reproducibility) at 4 $4{ }^{\circ} \mathrm{C}$ & 14.43 & 96.72 \\
MQC2 $=1989.20$ & & 1034.42 & 104.00 \\
HQC $=3978.41$ & & 2119.15 & 106.53 \\
\hline
\end{tabular}

\begin{tabular}{|llll|}
\hline $\begin{array}{l}\text { Table 10. Dilution integrity assessment of DNDI-VL-2098 in rat, mouse and dog blood. } \\
\text { Sample replicate }\end{array}$ & $\begin{array}{l}\text { Sprague-Dawley rat blood (194771.25 } \\
\text { ng/ml) }\end{array}$ & $\begin{array}{l}\text { Swiss albino mouse blood (202980.00 } \\
\text { ng/ml) }\end{array}$ & Beagle dog blood (203477.50 $\mathbf{n g} / \mathbf{m l})$ \\
\hline 1 & 217121.49 & 189826.79 & 198819.49 \\
\hline 2 & 200587.99 & 190872.80 & 196213.40 \\
\hline 3 & 209370.21 & 201931.27 & 200425.87 \\
\hline 4 & 212299.24 & 183477.90 & 188544.02 \\
\hline 5 & 203348.97 & 177377.71 & 193128.40 \\
\hline 6 & 199182.32 & 183949.88 & 198391.72 \\
\hline Mean & 206985.04 & 187906.06 & 195920.48 \\
\hline SD & 7095.11 & 8429.75 & 4406.89 \\
\hline$\%$ CV & 3.43 & 4.49 & 2.25 \\
\hline \%RE & 6.27 & -7.43 & -3.71 \\
\hline $\mathrm{n}$ & 6 & 6 & 6 \\
\hline
\end{tabular}

for QC samples that exceeded the standard curve limits by diluting them 50 -fold with blank matrix. The precision and accuracy for six sets of diluted QC samples were within the acceptable range for all species.

\section{Pharmacokinetic study}

The sensitivity and selectivity of the bioanalytical method was successfully evaluated by analyzing blood samples from a rat PK study. The pharmacokinetic parameters are presented in Table 11 and curves for the mean concentration of DNDI-VL-2098 in rat blood versus time are presented in Figure 5 . The doses administered were 1 and $50 \mathrm{mg} / \mathrm{kg}$ 
Table 11. Pharmacokinetic parameters of DNDI-VL-2098 following intravenous bolus and oral gavage administration of dose formulations in male Sprague Dawley rats.

\begin{tabular}{|c|c|c|c|c|c|c|c|c|}
\hline $\begin{array}{l}\text { Dose }(\mathrm{mg} / \mathrm{kg} \text { ) } \\
\text { (Route) }\end{array}$ & $\mathrm{T}_{\max }^{\dagger}(\mathrm{h})$ & $\mathrm{C}_{0} / \mathrm{C}_{\max }(\mathrm{ng} / \mathrm{ml})$ & $\begin{array}{l}\text { AUC }_{\text {last }} \\
\text { (ng.h/ml) }\end{array}$ & $\mathrm{AUC}_{\text {inf }}(\mathrm{ng} \cdot \mathrm{h} / \mathrm{ml})$ & $\mathrm{CL}(\mathrm{ml} / \mathrm{min} / \mathrm{kg})$ & $V_{s s}(L / k g)$ & $\mathrm{T}_{1 / 2}(\mathrm{~h})$ & $\% F$ \\
\hline 1 (IV) & NA & $546 \pm 100$ & $1700 \pm 271$ & $1910 \pm 270$ & $8.83 \pm 1.23$ & $2.32 \pm 0.61$ & $3.14 \pm 0.77$ & NA \\
\hline $50(\mathrm{PO})$ & $4.0(4.0-6.0)$ & $7040 \pm 2090$ & $75300 \pm 10100$ & $75400 \pm 10100$ & NA & & $4.80 \pm 0.23$ & 89.0 \\
\hline
\end{tabular}

$\dagger$ Expressed as median value (range: minimum and maximum $T_{\max }$ )

$A \cup C_{\text {inf }}$ : Area under the plasma concentration-time curve from zero hour to infinity; $A \cup C_{\text {last }}$ : Area under the plasma concentration-time curve from zero hour to last detected concentration; $\mathrm{CL}$ : Plasma clearance; $\mathrm{C}_{\max }$ : Peak plasma concentration; $\mathrm{C}_{0}$ : Back extrapolated plasma concentration at zero time after intravenous bolus administration; \%F: Percent bioavailability; $T_{1 / 2}$ (h): Elimination half life; $\mathrm{T}_{\max }$ : Time to reach peak plasma concentration; $\mathrm{V}_{\mathrm{ss}}$ : Volume of distribution at study state.

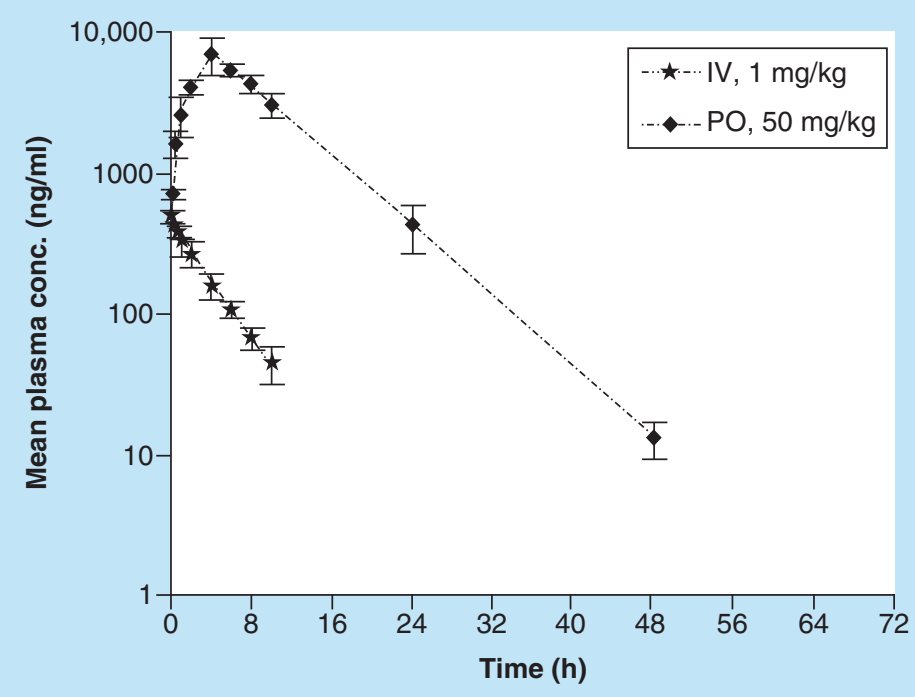

Figure 5. Representative blood concentration (mean \pm standard deviation) versus time profiles of DNDI-VL-2098 following intravenous bolus and oral gavage administration to male Sprague-Dawley rats as a semi-log plot.

for intravenous and oral route, respectively. The low dose used for the intravenous administration was a limitation of the solubility of DNDI-VL-2098 for the preparation of a solution formulation. The oral dose was selected to evaluate the PK profile at the efficacious dose.

The results suggest that for the IV route, the blood clearance was low $(8.83 \mathrm{ml} / \mathrm{min} / \mathrm{kg})$, which is approximately $16 \%$ of normal hepatic blood flow $(55 \mathrm{ml} / \mathrm{min} / \mathrm{kg})$ in rats. The volume of distribution at steady-state was high (approximately 3.31-fold higher compared with normal body water in rats) with an elimination half-life of $3.14 \mathrm{~h}$.

For the oral route of administration, the mean peak blood concentration was $511 \mathrm{ng} / \mathrm{ml}$, which was observed at around $4 \mathrm{~h}$, suggesting a moderate rate of oral absorption. The mean blood exposures (AUC last and $\mathrm{AUC}_{\text {inf }}$ ) were 1700 and $1910 \mathrm{ng} . \mathrm{h} / \mathrm{ml}$, respectively, and the oral bioavailability was high (89\%).

\section{Conclusion}

Since DNDI-VL-2098 was found to be unstable in plasma and whole blood in ex vivo conditions, this bioanalytical method required a unique sample collection and preparation procedure. To stabilize DNDI-VL-2098, an equal volume of $0.1 \mathrm{~N} \mathrm{HCl}$ was added immediately upon blood collection, and a two-step procedure was applied to extract DNDI-VL-2098 from the blood. The LC-MS/MS method for DNDI-VL-2098 described in this report was fully validated across three species, mouse, rat and dog, and was evaluated for its fitness for purpose in hamster blood. This assay has subsequently been used to analyze samples from various preclinical pharmacokinetic and toxicokinetic studies. 


\section{Future perspective}

A bioanalytical method with a two-step sample preparation approach, protein precipitation followed by liquidliquid extraction, was successful in yielding clean samples from hemolyzed blood for DNDI-VL-2098. This approach may be useful 'dirty' samples such as bile and samples with analytes that suffer from matrix effects. In the future, newer sample preparation techniques such as solid phase extraction may be applied to the extraction of DNDI-VL-2098 and other nitroimidazoles. The addition of 1:1 $0.1 \mathrm{~N} \mathrm{HCl}$ to whole blood stabilized the analyte for the desired period. DNDI-VL-2098 having been discontinued as an oral agent for treatment of visceral leishmaniasis, this bioanalytical method could be extended to other nitroimidazole derivatives plagued with similar ex vivo stability issues.

\section{Summary points}

Method development

- A robust, sensitive and quantitative method was developed and validated for the determination of DNDI-VL-2098 in mouse, rat and dog blood. The same method was successfully evaluated for its fitness of purpose in hamster blood.

- A novel approach was used to effectively stabilize the analyte DNDI-VL-2098 in whole blood by the addition of an equal proportion of $0.1 \mathrm{~N} \mathrm{HCl}$.

- A two-step sample preparation protocol was developed for the extraction of DNDI-VL-2098 from hemolyzed blood, which included extraction using protein precipitation followed by liquid-liquid extraction. This two-step process resulted in cleaner samples and helped to diminish previously observed matrix effects.

- The method was developed utilizing very low sample volumes $(50 \mu \mathrm{l})$, an isocratic mobile phase for chromatographic resolution and the structural analog DNDI-VL-2075 as an internal standard.

Application

- This is the first bioanalytical method reported for the quantification of DNDI-VL-2098 in mouse, rat, dog and hamster blood using an LC-ESI-MS/MS method.

- The method was successfully used to characterize the pharmacokinetic parameters of DNDI-VL-2098 in rat.

Financial \& competing interests disclosure

DNDI-VL-2098 analytical standard was synthesized and characterized at Advinus Therapeutics Ltd., Bangalore, India. The research was part of a collaborative program carried out at Advinus Therapeutics Ltd., and was funded by DNDi. For this work, DNDi received financial support from the Dutch Ministry of Foreign Affairs, The Netherlands and the Federal Ministry of Education and Research through KfW, Germany; and for its overall mission from UK aid, UK; Médecins sans Frontières (MSF) and the Swiss Agency for Development and Cooperation, Switzerland. The authors have no other relevant affiliations or financial involvement with any organization or entity with a financial interest in or financial conflict with the subject matter or materials discussed in the manuscript apart from those disclosed.

No writing assistance was utilized in the production of this manuscript.

Ethical conduct of research

The authors state that they have obtained appropriate institutional review board approval or have followed the principles outlined in the Declaration of Helsinki for all human or animal experimental investigations. In addition, for investigations involving human subjects, informed consent has been obtained from the participants involved.

\section{Supplementary data}

To view the supplementary data that accompany this paper please visit the journal website at: https://www.future-science.com/d oi/10.4155/bio-2019-0128

\section{References}

1. Hof H, Stroder J, Buisson JP, Royer R. Effect of different nitroheterocyclic compounds on aerobic, microaerophilic, and anaerobic bacteria. Antimicrob. Agents Chemother. 30(5), 679-683 (1986).

2. Grunberg E, Titsworth EH. Chemotherapeutic properties of heterocyclic compounds: monocyclic compounds with five-membered rings. Annu. Rev. Microbiol. 27, 317-346 (1973).

3. Editorial. The nitroimidazole family of drugs. Br. J. Vener. Dis. 54, 69-71 (1978). 
4. Edwards DI. Mechanisms of selective toxicity of metronidazole and other nitroimidazole drugs. Br. J. Vener. Dis. 56(5), 285-290 (1980).

5. Müller M. Mode of action of metronidazole on anaerobic bacteria and protozoa. Surgery 93(1 Pt 2), 165-71 (1983).

6. Greenwood D, Whitley R. Modes of action. In: Antibiotic and Chemotherapy: Anti-Infective Agents and Their Use in Therapy. Hodgson S, Clansey N (Ed.). Saunders, Elsevier Limited, Edinburgh, 11-24 (2002).

7. Peterson FJ, Mason RP, Hovsepian J, Holtzman JL. Oxygen-sensitive and-insensitive nitroreduction by Escherichia coli and rat hepatic microsomes. J. Biol. Chem. 254(10), 4009-4014 (1979).

8. Moreno SN, Mason RP, Docampo R. Distinct reduction of nitrofurans and metronidazole to free radical metabolites by Tritrichomonas foetus hydrogenosomal and cytosolic enzymes. J. Biol. Chem. 259(13), 8252-8259 (1984).

9. Xavier A, Lakshmanan M. Delamanid: a new armor in combating drug-resistant tuberculosis. J. Pharmacol. Pharmacother. 5(3), 222 (2014).

10. Reviriego C. Delamanid. Drugs Future 38(1), 7 (2013).

11. Gler MT, Skripconoka V, Sanchez-Garavito E et al. Delamanid for multidrug-resistant pulmonary tuberculosis. N. Engl. J. Med. 366(23), 2151-2160 (2012).

12. Shimokawa Y, Sasahara K, Koyama N et al. Metabolic mechanism of delamanid, a new anti-tuberculosis drug, in human plasma. Drug Metab. Dispos. 43(8), 1277-1283 (2015).

13. Sasahara K, Shimokawa Y, Hirao Y et al. Pharmacokinetics and metabolism of delamanid, a novel anti-tuberculosis drug, in animals and humans: importance of albumin metabolism in vivo. Drug Metab. Dispos. 43(8), 1267-1276 (2015).

14. Hirao Y, Koga T, Koyama N, Shimokawa Y, Umehara K. Liquid chromatography-tandem mass spectrometry methods for determination of delamanid in mouse plasma and lung. Am. J. Anal. Chem. 06(02), 98-105 (2015).

15. Meng M, Smith B, Johnston B, Carter S, Brisson J, Roth SE. Simultaneous quantitation of delamanid (OPC-67683) and its eight metabolites in human plasma using UHPLC-MS/MS. J. Chromatogr. B Anal. Technol. Biomed. Life Sci. 1002, 78-91 (2015).

16. Drugs for neglected diseases initiative. www.dndi.org/diseases-projects/portfolio/completed-projects/vl-2098/

17. Satam VS, Pedada SR, Kamaraj P et al. Development of a scalable process for the synthesis of DNDI-VL-2098: a potential preclinical drug candidate for the treatment of visceral leishmaniasis. Org. Process Res. Dev. 21(1), $52-59$ (2017).

18. U.S. Department of Health and Human Services Food and Drug Administration, Center for Drug Evaluation and Research (CDER) and Center for Veterinary Medicine (CVM), Bioanalytical Method Validation Guidance for Industry (2018). www.fda.gov/media/70858/download

19. European Medicines Agency. Guideline on bioanalytical method validation (2012). www.ema.europa.eu/en/documents/scientific-guideline/guideline-bioanalytical-method-validation_en.pdf

20. Viswanathan CT, Bansal S, Booth B et al. Workshop/conference report - quantitative bioanalytical methods validation and implementation: best practices for chromatographic and ligand binding assays. AAPS J. 9(1), E30-E42 (2007).

21. Upton RA. Simple and reliable method for serial sampling of blood from rats. J. Pharm. Sci. 833(1), 112-114 (1973).

22. Gu H, Liu G, Wang J, Aubry AF, Arnold ME. Selecting the correct weighting factors for linear and quadratic calibration curves with least-squares regression algorithm in bioanalytical LC-MS/MS assays and impacts of using incorrect weighting factors on curve stability, data quality, and assay performance. Anal. Chem. 86(18), 8959-8966 (2014). 